\title{
Translating SARS-CoV-2 wastewater-based epidemiology for prioritizing mass vaccination: a strategic overview
}

\author{
Tanmay Dharmadhikari $^{1} \cdot$ Rakeshkumar Yadav $^{1,2} \cdot$ Syed Dastager ${ }^{1,2} \cdot$ Mahesh Dharne $^{1,2}$ (D)
}

Received: 28 April 2021 / Accepted: 23 June 2021 / Published online: 1 July 2021

(C) The Author(s), under exclusive licence to Springer-Verlag GmbH Germany, part of Springer Nature 2021

\begin{abstract}
The inception of the novel coronavirus has forced the world into despair. Rapid progress has been made in addressing the situation, and various clinical diagnostic methods were developed for early detection of transmission. However, with a rapidly increasing number of infected populations worldwide, the testing of each individual was impractical. The wastewater-based epidemiology (WBE) has been implemented to evaluate disease outbreaks as an early warning system for pandemic preparedness. Numerous studies reported the presence of SARS-CoV-2 in the open drains and STPs across the globe via recovery efficiency of surrogate virus from existing virus concentration protocols. However, the such reported studies did not justify the use of WBE to identify or pinpoint the specific hotspots of transmission which could be prioritized for rapid efforts to contain or accelerate active vaccination efforts. Identifying precise locations of hotspots could be an essential aspect in controlling the outbreak and surge of wave by prioritizing the region for primary outbreak response. This article focuses on the issues relating to the primary focus for WBE that can be adapted, and its suitability for utilization in the mass vaccination program is discussed. Effective use of WBE information in terms of source tracking might be crucial as we move towards mass vaccination to control outbreaks of COVID-19 pandemic.
\end{abstract}

Keywords Wastewater $\cdot$ Epidemiology $\cdot$ SARS-CoV-2 $\cdot$ Vaccination $\cdot$ Policy making

\section{Introduction}

An outbreak of disease from pathogenic viruses has always caused human hardship. Mitigation of these diseases requires the combined action of their detection and prophylaxis.

\section{Highlights}

- Introduction to the wastewater-based epidemiology strategy

- Assessment of WBE strategy for SARS-CoV-2

- Proposition of SARS-CoV-2 WBE approach in mass vaccination program

- Back tracing approach to identify potential hotspots

Responsible Editor: Lotfi Aleya

Mahesh Dharne

ms.dharne@ncl.res.in

1 National Collection of Industrial Microorganisms (NCIM), Biochemical Sciences Division, CSIR-National Chemical Laboratory, Dr Homi Bhabha Road, Pashan, Pune, Maharashtra 411008, India

2 Academy of Scientific and Innovative Research (AcSIR), Ghaziabad, India
Viruses have caused outbreaks of public disasters, such as the 1920s' "Spanish" pandemic influenza (H1N1) which devoured the life of more than 50 million people (Russell and Webster 2005). Several threatening viral outbreaks have also occurred, such as Ebola, influenza, Zika, Middle East respiratory syndrome (MERS), severe acute respiratory syndrome (SARS), and Crimean-Congo hemorrhagic fever (CCHF).

The world has recently shattered into confusion and disruption over a novel respiratory distress virus that originated in China and triggered a cascade of reactions resulting in a pandemic (Chan et al. 2020). In the last few months, the minds of humanity as a whole have had a sense of immense fear. Scientists are vying, health workers have sleepless nights, and the governments worldwide are on their feet to tackle the outbreak of a novel virus. The causative agent is a positive-sense single-stranded enveloped RNA virus classified later as severe acute respiratory syndrome-coronavirus 2 (SARS-CoV-2) or 2019-novel coronavirus (2019-nCoV) (Gorbalenya et al. 2020). Coronaviruses have the largest genomes among RNA viruses that possess a high risk of broadening pathogenicity due to their distinct replicative 
mechanism of obtaining part of the host genome (Woo et al. 2005). Zhu et al. (2020) initially characterized 2019-nCoV from the initial patient samples through multiplex reverse transcriptase polymerase chain reaction (rt-PCR), virus isolation, transmission electron microscopy (TEM), and genome analysis identifying the novel species with distinct $R d R p$ gene of pan $\beta-C o V$. Consequently, various assays were developed worldwide from accessible knowledge facilitating its clinical detection worldwide. Tang et al. (2020) suggested the presence of 2019-nCoV in the stool samples from symptomatic and asymptomatic patients, which had a concern about the communicable nature of the virus entering the sewage. The viral load in feces was also higher than respiratory track; however, their infectivity was ambiguous. Pandemic declaration meant the spread of the virus throughout the world, but the clinical assessment of each individual became increasingly impractical. Additional diagnostic tools were therefore needed to evaluate the spread of the virus. The epidemiological wastewater approach (WBE) to illicit drug use was studied in Italy by Zuccato et al. (2005) for surface water to monitor public drug abuse. It was suggested that the work should recognize the limitations of self-reporting the illicit drug use among the public. Chopra and Arora (2020) pointed out that COVID-19 acted similar to tuberculosis in the case of social stigma, where public fear of an unexplored virus leads to discrimination against infected individuals and health professionals. This has led to people hiding their infections, fluctuating in the dynamics of infection, where the actual number of infected individuals in society can remain undisclosed, increasing the potential risk to society as a whole. Hence, WBE work was started quickly, and the research community was flooded with multiple studies detecting 2019-nCoV in wastewaters.

Although several studies have detected 2019-nCoV using the WBE approach, backtracking to an affected precise geographic location still remains a mystery. This raises the question of whether the current approach to the WBE is rationalizing. This article reflects instrumentality of WBE around the globe while trying to ascertain the benefits to society, especially concerning the mass vaccination program.

\section{Wastewater-based epidemiology for virus surveillance}

Several institutions worldwide have adapted a wastewaterbased monitoring tool (WBE) for the analysis of outbreaks involving poliovirus, hepatitis virus, and other enteric viruses, where a proportion has also analyzed the recovery efficiency of their protocols by sampling quantified surrogate viruses. Heijnen and Medema (2011) worked towards influenza A viral detection in sewage where pandemic influenza A (H1N1) was not detected in the samples. However, it was also discussed how a wastewater-based tracking tool is essential and has currently been neglected. Work with several other enveloped and non-enveloped viruses have also been carried out significantly in different parts of the world. La Rosa et al. (2010) carried out a follow-up of the hepatitis E virus (HEV) from wastewater while using feline calicivirus as process control for the entire study to evaluate the recovery of samples and detected the presence of HEV throughout Italy.

\section{Wastewater epidemiology for 2019-nCoV}

Peccia et al. (2020) suggested that the presence of virus particle in wastewater could not be directly correlated to gain insight into the number of infected individuals in the population. However, a correlation of fluctuation between the 2019-nCoV virus titer and the number of infected individuals has been observed throughout the wastewater samples collected from the sewage treatment plant, indicating WBE can help understand the community transmission dynamics for better preparedness. Similarly, WBE has been employed worldwide to identify the presence of $2019-\mathrm{nCoV}$ in wastewater. 2019$\mathrm{nCoV}$ was recently introduced into the virus inventory, and recovery efficiency through various standard virus purification protocols had to be optimized to improve the wastewater-based monitoring tool. The significant Virus Concentration Protocol Diagnostic Candidacy was promptly initiated. Ahmed et al. (2020a, b, c) implemented seven evidence-based virus concentration protocols that revealed recovery efficacy for murine hepatitis virus (MHV) as a surrogate for 2019-nCoV. The virus adsorption protocol involving $\mathrm{MgCl}_{2}$ and electronegative membrane filters yielded the highest recovery of MHV seed in the sample and was considered efficient and feasible with low PCR inhibition products co-precipitated.

Ahmed et al. (2020a, b, c) provided the first confirmation of 2019-nCoV detection in wastewater in Australia using the electronegative membrane filtration protocol described earlier. The RT-qPCR products were also sequenced using the sequencing platforms, and positive sample titer was accessed to the deduced correlation with the dynamics of the infected population. However, due to differences in geographic distribution and viral load shedding patterns for 2019-nCoV, this was considered problematic. It was also noted that the exact viral titer in the sample was not deductible as the concentration methods were not evaluated, particularly for 2019-nCoV.

Similarly, the 2019-nCoV WBE was carried in many parts of the world. Westhaus et al. (2020) examined both the solid and liquid phases of wastewater in Germany and the ability of the isolated virus to infect the cell line showing cytopathic effect. Nemudryi et al. (2020) examined the genomic variants using the Oxford Nanopore NGS platform and observed the phylogenetic assessment of viral strains. Rimoldi et al. (2020) in Italy, Medema et al. (2020) in the Netherlands, Gonzalez et al. (2020) in the USA, Hata et al. (2020) in Japan, Trottier 
et al. (2020) in France, D'Aoust et al. (2021) in Canada, Manupati et al. (2020), Kumar et al. (2020) and Arora et al. $(2020 \mathrm{a}, \mathrm{b})$ in India, and others were involved in WBE using analog virus concentration protocols, rt-PCR assays, and confirmatory sequencing the rt-qPCR products. Huang et al. (2021) tested anal swab and surrounding samples from the hospital with infected individuals to conclude patients' release of viral particles as an indicator of the possibility of transmission. Gonçalves et al. (2020) in Slovenia examined the presence of 2019-nCoV in hospital wastewater, while Zhang et al. (2020) revealed the inefficiency of current disinfection protocols to remove 2019-nCoV from hospital wastewater. Hasan et al. (2020) conducted studies at 11 STPs and 38 wastewater access points (manholes) in the UAE, and Ahmed et al. (2020a, b, c) in Bangladesh focused on drainage water near the 2019-nCoV Isolation and Care unit to conclude the presence of 2019-nCoV.

\section{Discussion}

\section{Monitoring and back tracing infection hotspots}

Numerous articles have identified the presence of 2019-nCoV in the fecal matter of infected individuals as the virus finds a perfect niche in the human intestine owing to the presence of ACE2 receptors (Wang et al. 2020). Recently published WBE monitoring articles and research papers discuss concentration protocols suitable for concentration of viruses and molecular diagnosis focusing on 2019-nCoV. Due to the current pandemic situation of 2019-nCoV, the ubiquitous presence of $2019-\mathrm{nCoV}$ in the world is not difficult to conclude. Therefore, it can easily be deciphered that most of the world's sewage treatment plants could carry detectable virus genetic material. Thus, most of the studies detecting 2019-nCoV using WBE approach targeted sewage treatment plants (STPs) and drainage system associated with COVID-19 Care Units and Hospitals. However, the WBE articles only discussed the presence of viral genetic materials in untreated wastewater while at the same time assessing the efficacy of STP in the removal of viral particle confirmed by diagnostics. The trailing for the precise geographical locations for a higher infected population was not discussed in the best of our knowledge in any article. An advantageous result for WBE could be the backtracking of precise geographic areas.

\section{Wastewater risk and informing public}

A well-planned drainage system leaves no trace of common public or animals coming into contact with wastewater. However, many parts of the world do not have access to clean water or appropriate civil planning where the population can come into contact with wastewater, the water which has demonstrated presence of a high 2019-nCoV viral title in a number of research articles published worldwide. Infective competence study of 2019-nCoV from wastewater samples obtained from the STP or river system is also important. There are studies showing the course of virus titer in infected patients; however, the infectivity competence study from WBE remained concerned with probable future studies. The infectivity competence study could practically help us to monitor new emerging infections, while also prioritizing the required infectivity and source-trailing studies (Walsh et al. 2020). Although Rimoldi et al. 2020 studies have shown a result of cytopathic effect of 2019-nCoV on the VERO E6 cell line, with additional infection dynamics of 2019-nCoV being obtained, regular observations are also important.

This WBE tool may also be considered to prioritize people in the vicinity of wastewater for vaccination, as the virus does not discriminate between human-made divisions or classes, but may infect any individual who may act as a future transmission agent. Therefore, the WBE tool can also be used to provide the public with sufficient knowledge that can be made aware of wastewater risks, even if the infectivity of the virus present in wastewater is unclear.

\section{Recovery efficiency of 2019-nCoV for WBE and public health burden}

The quantification of the virus titer has an important aspect since it can be linked to the increasing infection dynamics in the population. However, the recovery of the virus from wastewater through the current standard virus concentration and recovery protocols, specifically for 2019-nCoV, was not reached as the positive results obtained confirmed the presence of the virus and, taking into account the need for an hour, the quantification assessment was considered possible for future results. Thus, the recovered virus titer mentioned in the entire 2019-nCoV wastewater literature would not be sufficient to track population dynamics and can only be useful for comparative analysis of areas with the most affected population. 2019-nCoV is a newly emerged virus infection, and many long-term health effects are uncertain at this point, but long-term health effects have been suggested as infectioncured people also complain about persistent health problems (Del Rio et al. 2020). Therefore, it is necessary to use information from WBE tool to avoid future health burdens among the population and inform public about the dangers of infections arising from wastewater.

\section{Tracking genomic variants using sequencing platforms}

The articles published for 2019-nCoV WBE mention virus titer, but variants in strains have not been studied with the best of our knowledge except for Nemudryi et al. (2020). 


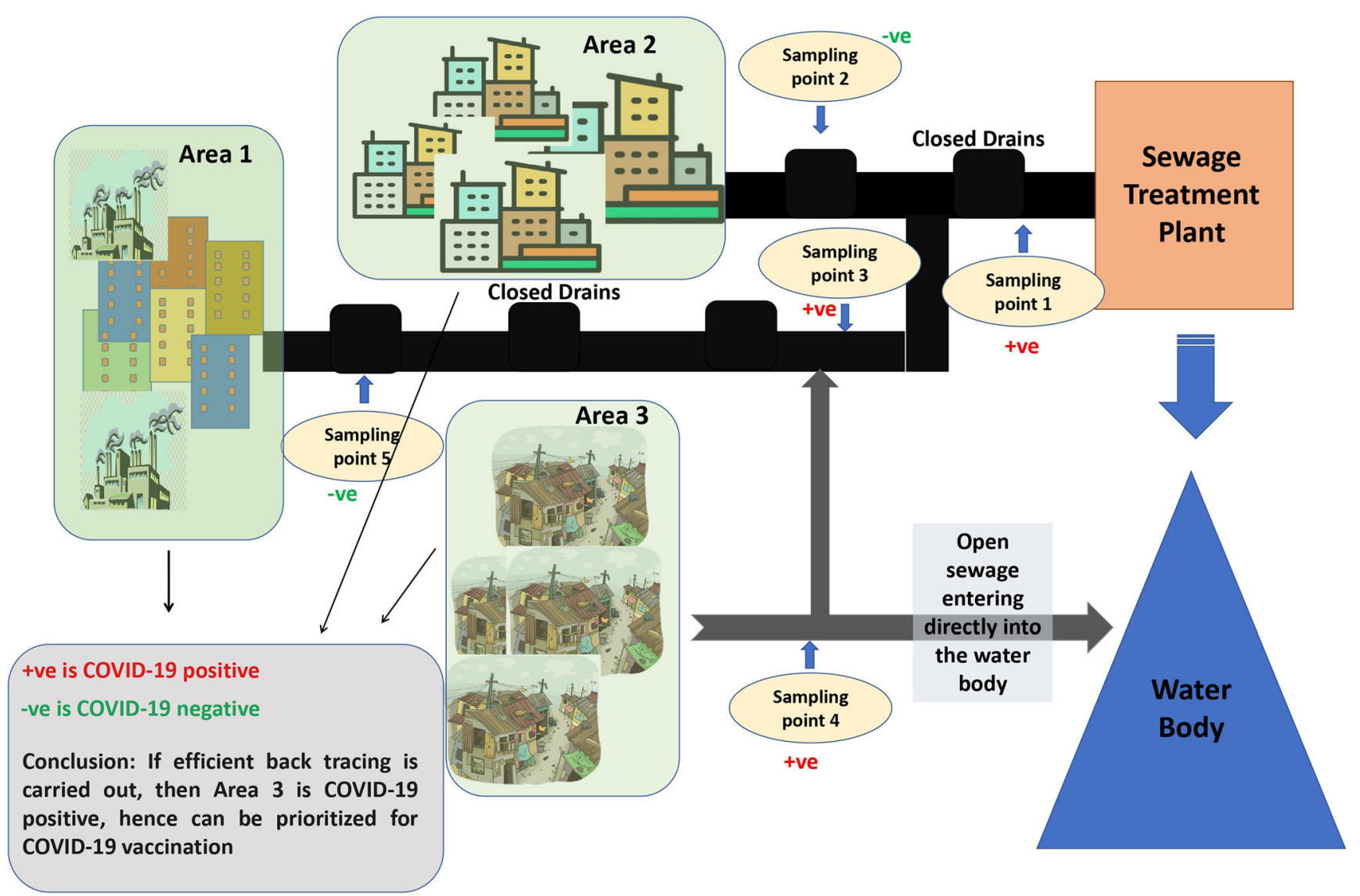

Fig. 1 Schematic illustrating use of WBE for determination of vaccination priority area

Mercatelli and Giorgi (n.d.) suggested that 2019-nCoV had developed into competent infectivity in humans and thus showed a low variability in genome mutations, while it was also noted that the presence of multiple strains circulating in the world had been observed when their genome was studied. However, there has been a recent addition of novel strains, such as those from the UK, which caused havoc as the data predicted the presence of strains from mid-September with increased infectivity capabilities (Wise n.d.). This determines the importance of genome sequencing to track the evolution of the virus in real time while accessing the pandemic situation. However, a WBE tool, along with sequencing platform such as Oxford Nanopore Sequencing, which does not require amplification of the sample's genomic material (Lu et al. 2016), can also be effectively included to track new variants entering wastewater. As a WBE tool can provide a pathway to infection dynamics, the virus isolated from wastewater can be traced to genomic variants and affected areas to increase our preparedness. The initiative can be used for WBE monitoring and sequencing as studies by Peccia et al. (2020) have shown that clinical data lag behind wastewater monitoring data.

\section{Assessment of priority areas for mass vaccination}

This current viral pandemic of 2019-nCoV calls for an emergency response to mass vaccination as an effort to better the well-being and survival of humanity. The discussed WBE strategy can be utilized to evaluate the primary concerns of the approach. The well-planned STPs have water sources from surrounding areas, and therefore, a tracking tool can be used to track the source endpoint for access to areas containing the largest number of infected individuals. However, the areas with open access to the drains can still be at considerable risk and can also be considered as a priority for vaccination. The WBE approach may be useful, especially when approaching the mass vaccination program to eradicate $2019-\mathrm{nCoV}$.

A sample of the water body and the STPs can be tested for viral presence. The source of the virus can be traced back to its origin. As shown in Fig. 1, a schematic of a fictional system can be suggested. If the sampling point 1 is positive for 2019$\mathrm{nCoV}$, the rest sampling points can be tested. In sampling points 2 and 3 , if point 3 is positive, area 2 may be considered safe. However, sampling point 3 may be traced to area 1 and 
area 3 for a positive viral source by sampling points 4 and 5 , which may conclude viral presence in area 3 . Area 3 can therefore be considered a priority for mass vaccination.

\section{Conclusion}

The study of a wastewater-based tracking tool carried out around the world can therefore be hailed as an essential aspect of the study of population dynamics of infectivity, as it can provide real-time information on viral loads present in the wastewater system. However, it is crucial to examine the source of higher viral load and the infectivity capacity of virus entering the system through the endpoint trailing to determine the geographical locations most affected. The presence of distinct variants in wastewater can also be analyzed in order to understand genomic variations in order to track the evolutionary aspects of the novel virus, while at the same time considering active public participation offering knowledge of preventive measures. The scope of improvement in the WBE approach may also help to deliver extensive knowledge to help with prioritizing the geographical areas for vaccination. The wastewater-based tracking tool has an immense potential to deliver value-added knowledge that has barely been exploited.

Acknowledgements Authors are indebted to the Director, CSIR-NCL for providing support. TD and RKY acknowledge SERB and University Grant Commission (UGC), India, respectively for fellowship support received.

\section{Availability of data and materials Not applicable.}

Author contribution All authors have read and review the manuscript for submission. TD: writing original draft; RKY: editing, review, and art design; SD: review and funding; MD: editing, review, funding, and corresponding author

Funding This work was supported by the Science Engineering and Research Board (SERB), New Delhi, India, under special COVID grant (CVD/2020/001002/GAP 329826) and by the National Chemical Laboratory (NCL) core funds (MLP 038526).

\section{Declarations}

Ethics approval and consent to participate Not applicable.

Consent for publication Not applicable.

Conflict of interest The authors declare no competing interests.

\section{References}

Ahmed F, Islam MA, Kumar M, Hossain M, Bhattacharya P, Islam MT, Hossen F, Hossain MS, Islam MS, Uddin MM, Islam MN (2020a)
First detection of SARS-CoV-2 genetic material in the vicinity of COVID-19 isolation centre through wastewater surveillance in Bangladesh. medRxiv. https://doi.org/10.1101/2020.09.14. 20194696

Ahmed W, Angel N, Edson J, Bibby K, Bivins A, O'Brien JW, Choi PM, Kitajima M, Simpson SL, Li J, Tscharke B (2020b) First confirmed detection of SARS-CoV-2 in untreated wastewater in Australia: a proof of concept for the wastewater surveillance of COVID-19 in the community. Sci Total Environ 18:138764. https://doi.org/10. 1016/j.scitotenv.2020.138764

Ahmed W, Bertsch P, Bivins A, Bibby K, Farkas K, Gathercole A, Haramoto E, Gyawali P, Korajkic A, McMinn BR, Mueller J (2020c) Comparison of virus concentration methods for the RTqPCR-based recovery of murine hepatitis virus, a surrogate for SARS-CoV-2 from untreated wastewater. Sci Total Environ 5: 139960. https://doi.org/10.1016/j.scitotenv.2020.139960

Arora S, Nag A, Rajpal A, Tiwari SB, Sethi J, Sutaria D, Rajvanshi J, Saxena S, Shrivastava SK, Kazmi AA, Tyagi VK (2020a) Detection of SARS-CoV-2 RNA in fourteen wastewater treatment systems in Uttarakhand and Rajasthan States of North India. medRxiv. https:// doi.org/10.1101/2020.09.18.20197178

Arora S, Nag A, Sethi J, Rajvanshi J, Saxena S, Shrivastava SK, Gupta AB (2020b) Sewage surveillance for the presence of SARS-CoV-2 genome as a useful wastewater based epidemiology (WBE) tracking tool in India. Water Sci Technol 82(12):2823-2836. https://doi.org/ 10.1101/2020.06.18.20135277

Chan JF, Yuan S, Kok KH, To KK, Chu H, Yang J, Xing F, Liu J, Yip CC, Poon RW, Tsoi HW (2020) A familial cluster of pneumonia associated with the 2019 novel coronavirus indicating person-toperson transmission: a study of a family cluster. Lancet 395(10223):514-523. https://doi.org/10.1016/S0140-6736(20) 30154-9

Chopra KK, Arora VK (2020) Covid-19 and social stigma: role of scientific community. Indian J Tuberc 67:284-285. https://doi.org/10. 1016/j.ijtb.2020.07.012

D'Aoust PM, Mercier E, Montpetit D, Jia JJ, Alexandrov I, Neault N, Baig AT, Mayne J, Zhang X, Alain T, Langlois MA (2021) Quantitative analysis of SARS-CoV-2 RNA from wastewater solids in communities with low COVID-19 incidence and prevalence. Water Res 188:116560. https://doi.org/10.1016/j.watres.2020. 116560

Del Rio C, Collins LF, Malani P (2020) Long-term health consequences of COVID-19. Jama. 324(17):1723-1724. https://doi.org/10.1001/ jama.2020.19719

Gonçalves J, Koritnik T, Mioč V, Trkov M, Bolješič M, Berginc N, Prosenc K, Kotar T, Paragi M (2020) Detection of SARS-CoV-2 RNA in hospital wastewater from a low COVID-19 disease prevalence area. Sci Total Environ 755:143226. https://doi.org/10.1016/j. scitotenv.2020.143226

Gonzalez R, Curtis K, Bivins A, Bibby K, Weir MH, Yetka K, Thompson H, Keeling D, Mitchell J, Gonzalez D (2020) COVID-19 surveillance in Southeastern Virginia using wastewater-based epidemiology. Water Res 186:116296. https://doi.org/10.1016/j.watres.2020. 116296

Gorbalenya A, Baker S, Baric R, de Groot R, Drosten C, Gulyaeva A, Haagmans B, Lauber C, Leontovich A, Neuman B, Penzar D (2020) Coronaviridae Study Group of the International Committee on Taxonomy of Viruses. The species severe acute respiratory syndrome-related coronavirus: classifying 2019-nCoV and naming it SARS-CoV-2. Nat Microbiol 2020:03-04. https://doi.org/10. 1038/s41564-020-0695-Z

Hasan SW, Ibrahim Y, Daou M, Kannout H, Jan N, Lopes A, Alsafar H, Yousef AF (2020) Detection and quantification of SARS-CoV-2 RNA in wastewater and treated effluents: surveillance of COVID19 epidemic in the United Arab Emirates. Sci Total Environ 19: 142929. https://doi.org/10.1016/j.scitotenv.2020.142929 
Hata A, Hara-Yamamura H, Meuchi Y, Imai S, Honda R (2020) Detection of SARS-CoV-2 in wastewater in Japan during a COVID-19 outbreak. Sci Total Environ 10:143578. https://doi.org/ 10.1016/j.scitotenv.2020.143578

Heijnen L, Medema G (2011) Surveillance of influenza A and the pandemic influenza A (H1N1) 2009 in sewage and surface water in the Netherlands. J Water Health 9(3):434-442. https://doi.org/10.2166/ wh.2011.019

Huang Y, Ding Z, Chen Q, Wu L, Guo L, Zhao C, Sha L, Sun H (2021) Environmental virus detection associated with asymptomatic SARS-CoV-2-infected individuals with positive anal swabs. Sci Total Environ 753:142289. https://doi.org/10.1016/j.scitotenv. 2020.142289

Kumar M, Patel AK, Shah AV, Raval J, Rajpara N, Joshi M, Joshi CG (2020) First proof of the capability of wastewater surveillance for COVID-19 in India through detection of genetic material of SARSCoV-2. Sci Total Environ 746:141326. https://doi.org/10.1016/j. scitotenv.2020.141326

La Rosa G, Pourshaban M, Iaconelli M, Vennarucci VS, Muscillo M (2010) Molecular detection of hepatitis E virus in sewage samples. Appl Environ Microbiol 76(17):5870-5873. https://doi.org/10. 1128/AEM.00336-10

Lu H, Giordano F, Ning Z (2016) Oxford Nanopore MinION sequencing and genome assembly. Genomics Proteomics Bioinformatics 14(5): 265-279. https://doi.org/10.1016/j.gpb.2016.05.004

Manupati H, Kiran U, Kuncha SK, Kopperi H, Gokulan CG, Mishra RK (2020) Comprehensive surveillance of SARS-CoV-2 spread using wastewater-based epidemiology studies. medRxiv. https://doi.org/ 10.1101/2020.08.18.20177428

Medema G, Heijnen L, Elsinga G, Italiaander R, Brouwer A (2020) Presence of SARS-Coronavirus-2 in sewage. MedRxiv. https://doi. org/10.1101/2020.03.29.20045880

Mercatelli D, Giorgi FM Geographic and genomic distribution of SARSCoV-2 mutations. https://doi.org/10.3389/fmicb.2020.01800

Nemudryi A, Nemudraia A, Wiegand T, Surya K, Buyukyoruk M, Cicha C, Vanderwood KK, Wilkinson R, Wiedenheft B (2020) Temporal detection and phylogenetic assessment of SARS-CoV-2 in municipal wastewater. Cell Rep Med 1(6):100098. https://doi.org/10.1016/ j.xcrm.2020.100098

Peccia J, Zulli A, Brackney DE, Grubaugh ND, Kaplan EH, CasanovasMassana A, Ko AI, Malik AA, Wang D, Wang M, Warren JL (2020) Measurement of SARS-CoV-2 RNA in wastewater tracks community infection dynamics. Nat Biotechnol 38(10):11641167. https://doi.org/10.1038/s41587-020-0684-z

Rimoldi SG, Stefani F, Gigantiello A, Polesello S, Comandatore F, Mileto D, Maresca M, Longobardi C, Mancon A, Romeri F, Pagani C (2020) Presence and infectivity of SARS-CoV-2 virus in wastewaters and rivers. Sci Total Environ 744:140911. https://doi. org/10.1016/j.scitotenv.2020.140911
Russell CJ, Webster RG (2005) The genesis of a pandemic influenza virus. Cell. 123(3):368-371. https://doi.org/10.1016/j.cell.2005.10. 019

Tang A, Tong ZD, Wang HL, Dai YX, Li KF, Liu JN, Wu WJ, Yuan C, Yu ML, Li P, Yan JB (2020) Detection of novel coronavirus by RTPCR in stool specimen from asymptomatic child, China. Emerg Infect Dis 6:1337-1339. https://doi.org/10.3201/eid2606.200301

Trottier J, Darques R, Mouheb NA, Partiot E, Bakhache W, Deffieu MS, Gaudin R (2020) Post-lockdown detection of SARS-CoV-2 RNA in the wastewater of Montpellier, France. One Health 10:100157. https://doi.org/10.1016/j.onehlt.2020.100157

Walsh KA, Jordan K, Clyne B, Rohde D, Drummond L, Byrne P, Ahern S, Carty PG, O'Brien KK, O'Murchu E, O'Neill M (2020) SARS$\mathrm{CoV}-2$ detection, viral load and infectivity over the course of an infection: SARS-CoV-2 detection, viral load and infectivity. J Infect 81:357-371. https://doi.org/10.1016/j.jinf.2020.06.067

Wang Q, Zhang Y, Wu L, Niu S, Song C, Zhang Z, Lu G, Qiao C, Hu Y, Yuen KY, Wang Q (2020) Structural and functional basis of SARSCoV-2 entry by using human ACE2. Cell. 181:894-904.e9. https:// doi.org/10.1016/j.cell.2020.03.045

Westhaus S, Weber FA, Schiwy S, Linnemann V, Brinkmann M, Widera M, Greve C, Janke A, Hollert H, Wintgens T, Ciesek S (2020) Detection of SARS-CoV-2 in raw and treated wastewater in Germany-suitability for COVID-19 surveillance and potential transmission risks. Sci Total Environ 751:141750. https://doi.org/10. 1016/j.scitotenv.2020.141750

Wise J. (n.d.) Covid-19: New coronavirus variant is identified in UK. https://doi.org/10.1136/bmj.m4857

Woo PC, Lau SK, Chu CM, Chan KH, Tsoi HW, Huang Y, Wong BH, Poon RW, Cai JJ, Luk WK, Poon LL (2005) Characterization and complete genome sequence of a novel coronavirus, coronavirus HKU1, from patients with pneumonia. J Virol 79(2):884-895. https://doi.org/10.1128/JVI.79.2.884-895.2005

Zhang D, Ling H, Huang X, Li J, Li W, Yi C, Zhang T, Jiang Y, He Y, Deng S, Zhang X (2020) Potential spreading risks and disinfection challenges of medical wastewater by the presence of Severe Acute Respiratory Syndrome Coronavirus 2 (SARS-CoV-2) viral RNA in septic tanks of Fangcang Hospital. Sci Total Environ 741:140445. https://doi.org/10.1016/j.scitotenv.2020.140445

Zhu N, Zhang D, Wang W, China Novel Coronavirus Investigating and Research Team (2020) A novel coronavirus from patients with pneumonia in China, 2019. N Engl J Med 382:727-733. https:// doi.org/10.1056/NEJMoa2001017

Zuccato E, Chiabrando C, Castiglioni S, Calamari D, Bagnati R, Schiarea S, Fanelli R (2005) Cocaine in surface waters: a new evidence-based tool to monitor community drug abuse. Environ Health 4(1):14. https://doi.org/10.1186/1476-069X-4-14

Publisher's note Springer Nature remains neutral with regard to jurisdictional claims in published maps and institutional affiliations. 